\title{
Water Quality Monitoring System Implemented With IoT
}

\author{
Kartik Maheshwari ${ }^{1}$, Adrija Chakraborty ${ }^{2}$ \\ ${ }^{1}$ U.G. Student, Vellore Institute of Technology, Vellore, India, karthik.maheshwari2018@ vitsudent.ac.in \\ ${ }^{2}$ U.G. Student, Vellore Institute of Technology, Vellore, India, adrija.chakraborty2018@ vitstudent.ac.in
}

\begin{abstract}
Monitoring the quality of water and its proper management is crucial for any industrial and economic application. The global shortage of water demands a sustainable solution to optimize its usage. The Internet of Things provides a robust and cost-effective solution for real-time monitoring of various parameters of water. The paper aims to implement an intelligent water quality monitoring system with the aid of IoT. The proposed system was successfully implemented to determine the turbidity, TDS, flow rate and the level of water for a given sample. The data obtained from the sensors are uploaded to the ThingSpeak dashboard for online monitoring purpose. Besides, an SMS alert is sent to the user whenever the turbidity and TDS values have crossed the threshold limit defined for good quality water.
\end{abstract}

Key words : IoT, sensors, TDS, ThingSpeak, turbidity.

\section{INTRODUCTION}

Water is undoubtedly one of the most vital environmental elements necessary to sustain our existence. Due to the exponential growth in population and improper management of water resources, there has been an acute shortage of water in different places around the globe. Besides, water pollution has adversely affected the lives of several organisms and is one of the foremost reasons for rise in mortality rate and outbreak of diseases worldwide.

Thus assessing the quality of water and its proper management is of paramount importance. In order to cope up with the huge demand for water, we need high-quality technology which can monitor the quality of water as well as ensure its availability. Such a system should be capable of monitoring different parameters of water like TDS, turbidity etc as well as measure the level and flow of water in different reservoirs for proper management. The traditional system for water quality monitoring and management relied heavily on manual work with no real-time monitoring available. This resulted in efficiency compromise and is not suitable to scale up well with the digital age. [1]
This paper establishes an IoT based system for monitoring various parameters related to water quality and management of water resources. Our embedded system consists of various sensors for measuring the flow and level of water along with its TDS and turbidity for accessing the quality of the water. The information obtained from these sensors is processed by the Arduino microcontroller, interfaced with an Ethernet shield and is uploaded to the ThingSpeak IoT platform. Real time monitoring can be performed from its dashboard from anywhere in the world. Besides, warning notifications will be sent to the user whenever the quality of water is poorer than expected. In this way, we'll be able to manage multiple water reservoirs and access the water quality of the water.

\section{LITERATURE SURVEY}

The implementation of a robust and cost-effective water monitoring system demands a good level of research and development. Many researchers have proposed different models in order to implement such a system.

Mohammad Salah Uddin Chowdury et al. [2] have proposed a system for monitoring the quality of water in a river with the aid of an embedded system consisting of wireless sensor network and IoT. Deep learning models have been used to assess the quality of water and SMS alert is sent in case the value of a sensor has crossed the threshold. Soundarya Pappu et al. [3] have used a $\mathrm{pH}$ and a TDS sensor to determine the quality of water with the Arduino microcontroller and the Raspberry Pi3. K-means clustering algorithm is used to predict the quality of water based on the sensed values.

Thinagaran Perumal, Md Nasir Sulaiman and Leong.C.Y [4] have implemented a system to monitor water level with IoT. The water level is measured using a sensor and is fed to a web-based dashboard. Twitter is used for sending necessary alerts to the users. Nikhil Kumar Koditala and Purnendu Shekar Pandey [5] have devised a model for regulating the temperature of water by predicting the temperature of the surrounding environment using machine learning. Besides, the quality of water is analyzed by sensors measuring $\mathrm{pH}$ and turbidity. The data is stored in Azure Event Hub and PowerBI is used for displaying the values obtained from the sensors. Juan Huan et al. [6] have used STM32L151C8 
microcontroller for real-time monitoring of temperature, dissolved oxygen and $\mathrm{pH}$ of a water sample. A cloud-platform is designed using Java for real-time monitoring.

Abbas Hussien Miry and Gregor Alexander Aramice [7] have used ThingSpeak for monitoring and analysis of the TDS and Turbidity of water. When the values of these parameters are not within a normal range, a warning message is notified to the user through IFTTT. Yiheng Chen and Dawei Han [8] have depicted how a water management system can be implemented through IoT in urban areas for developing a smart city. They have measured different parameters of water like dissolved oxygen, turbidity, $\mathrm{pH}$ and conductivity and have also employed a camera system to get a video of the surface of water. Sathish Pasika and Sai Teja Gandla [9] have devised an IoT system based on the ThingSpeak application for water quality monitoring. An Arduino Mega and NodeMCU microcontrollers are used to process the readings from the sensors and upload them to the ThingSpeak server. Tongxin Shu et al. [10] have developed an energy efficient system for automatic water quality monitoring. They have applied a data-driven adaptive sampling algorithm (DDASA) in order to the efficiency of power consumption while acquiring the turbidity and dissolved oxygen of water. Kamarul Hafiz Kamaludin and Widad Ismail [11] have used RFID and wireless sensor networks to perform real time monitoring of a lake. The $920 \mathrm{MHz}$ Digi-mesh protocol is used for its unique property of surpassing the signal attenuation.

\section{METHODOLOGY}

To design the proposed water quality monitoring system various water monitoring sensors and water quality parameters were investigated.

The initial step is to determine the various parameters which would be monitored for the assessment of the water quality and whether the water quality is within the specified rules and regulations of the World Health Organization(WHO). It was determined that water parameters such as nitrate levels, free chlorine concentration and dissolved oxygen cannot be monitored easily and/or required frequent maintenance and calibration to sustain accurate readings over long periods of time. Hence this proposed project would not be feasible for long-term real time water quality monitoring.

The sensors used for water quality monitoring and its management are as follows:

1. The water flow sensor (YF-S201) is based on hall-effect and this flow sensor consists of an obstruction rotor to measure the flow rate. It operates on $5 \mathrm{v}$ dc voltage and the hall-effect sensor gives the corresponding pulse signal output. Each pulse corresponds to an approximate flow of $2.25 \mathrm{ml}$ of liquid. Each pulse is a square wave and is converted to $\mathrm{L} / \mathrm{min}$ by using the formula: pulse frequency $(\mathrm{Hz}) / 7.5=$ flow rate in $\mathrm{L} / \mathrm{min}$. Velocity depends on the pressure that forces the through pipelines.

2. The water level sensor consists of series of exposed parallel conductors, together acts as a variable resistor whose resistance varies according to the water level. This sensor can be used to measure the water level, to monitor a sump pit, detect rainfall or detect leakage. It consists of a series of exposed parallel conductors, together acts as a variable resistor whose resistance varies according to the water level. The change in resistance corresponds to the distance from the top of the sensor to the surface of the water. The resistance is inversely proportional to the height of the water.

3. A TDS meter is basically an electrical charge (EC) meter whereby two electrodes equally spaced apart are inserted into water and used to measure charge. The result is interpreted by the TDS meter and converted into a ppm figure.

4. The turbidity sensor detects water quality by measuring the level of turbidity. It is able to detect suspended particles in water by measuring the light transmittance and scattering rate which changes with the amount of total suspended solids (TSS) in water. As the TTS increases, the liquid turbidity level increases.

The project implementation is divided in two main parts: hardware and the software implementation. The hardware setup is shown in figure 1. It includes the Arduino Uno interfaced with Ethernet Shield as microcontroller, Water flow sensor, Water level sensor, Turbidity and TDS sensor. Water samples with different levels of impurities are used for analysis. The microcontroller processes the data captured by the turbidity, TDS and flow sensors and then sends the data to the ThingSpeak Platform.

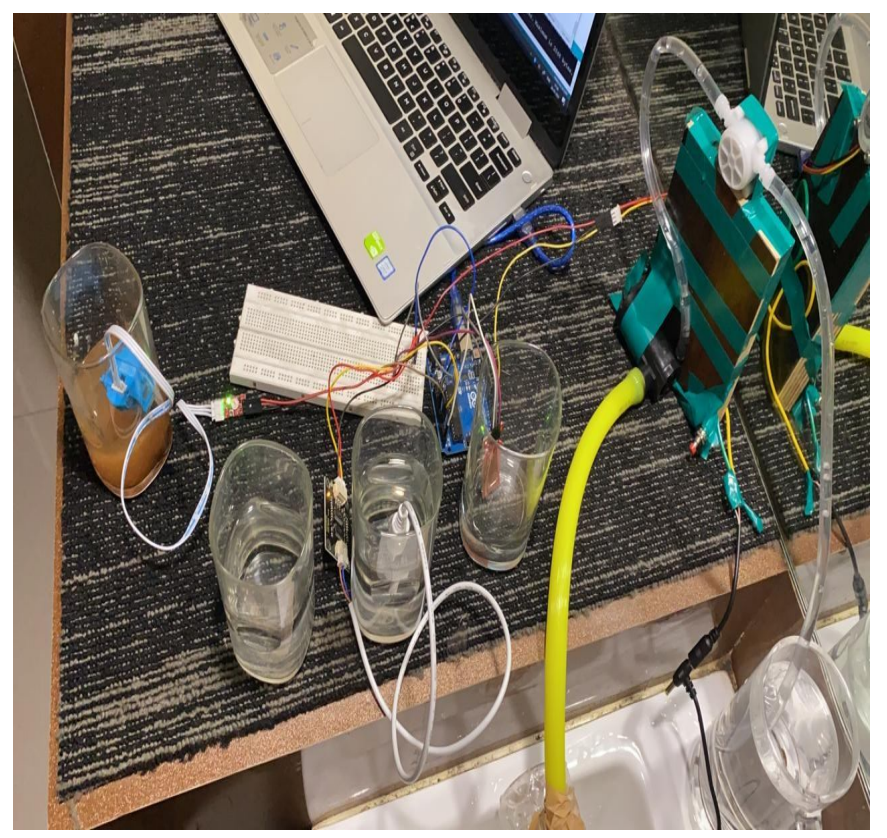

Figure 1: Hardware setup for the system 
If the turbidity and the TDS of the water sample are not within the safety limit, a warning SMS is automatically sent to the user through an applet made from the IFTTT (If This, Then That) platform. The IFTTT platform enables us to design custom applets which can be triggered depending on a specific condition. The configurations made in the IFTTT platform for sending SMS for high TDS and turbidity values are shown in figures 2 and 3.

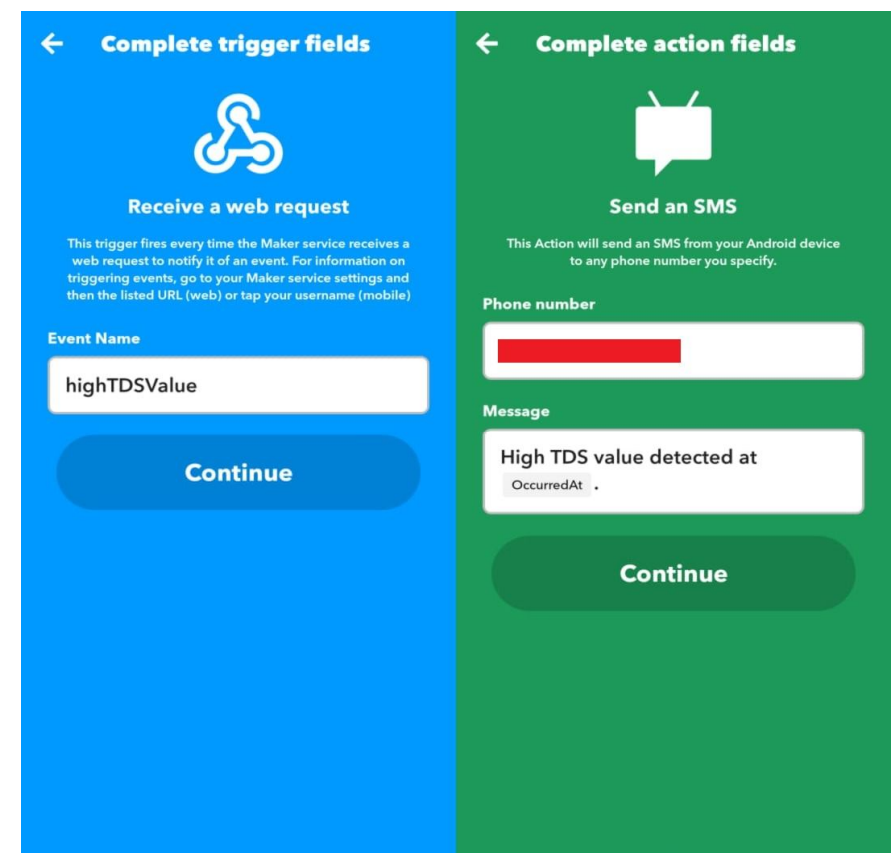

Figure 2: Applet for sending SMS for high TDS value configured using IFTTT.

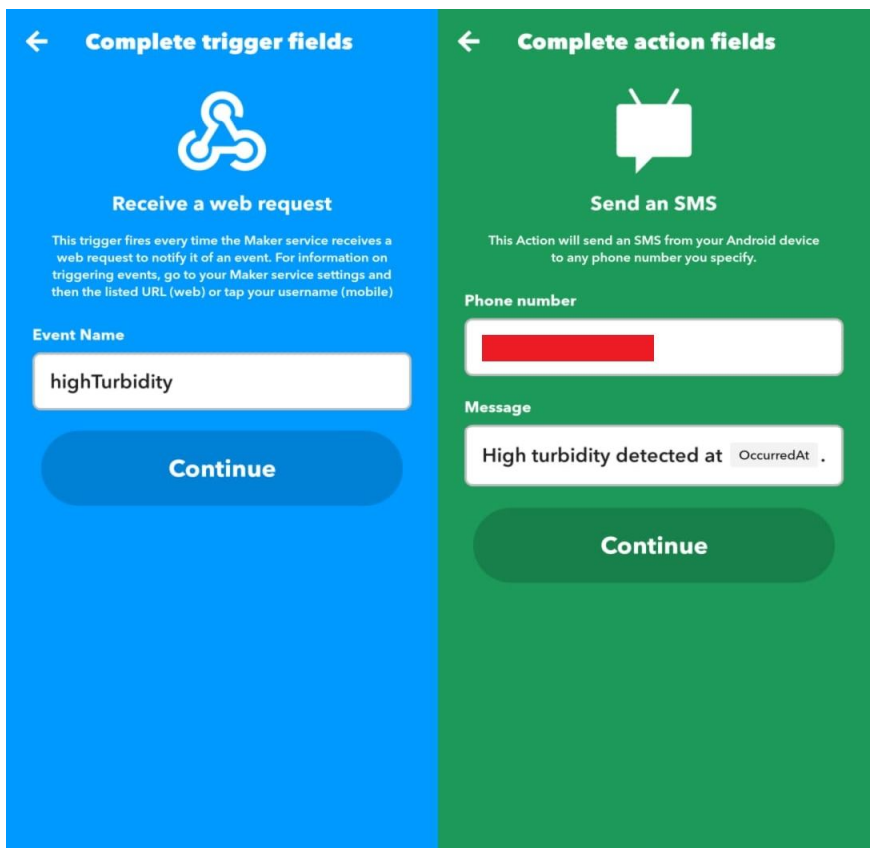

Figure 3: Applet for sending SMS for high turbidity value configured using IFTTT.

\section{RESULTS}

The system implemented with the aid of IoT is ideal for real time water monitoring. This is shown in the form of the graphs that are generated by ThingSpeak. The turbidity of water is its clarity. If any mud, slit or sand particles etc. are mixed with the water, its quality varies. According to the water quality norms, normal water ranges from 0 NTU (Nephelometric Turbidity Units) to $5 \mathrm{NTU}$ and also maximum of up to $5 \mathrm{NTU}$ is permissible. If the water goes over 6 NTU up to 3000 NTU it is classified as turbid or mud mixed water. Figure: 4 shows the measurement of Turbidity of water.

Total dissolved solids (TDS) comprise in organic salts (principally calcium, magnesium, potassium, sodium, bicarbonate, chlorides, and sulphate) and some small amounts of organic matter that are dissolved in water. Figure5: TDS level Measurement as per WHO (world Health Organization) TDS ranges from 0 to above 1200 . The TDS is measured in ppm. TDS range less than 300ppm range is considered as excellent for drinking water, 300- $400 \mathrm{ppm}$ is good, 600-900 ppm is fair, 900-1200 is poor and above 1200 is unacceptable. And figure 5 shows the measurement of TDS range.

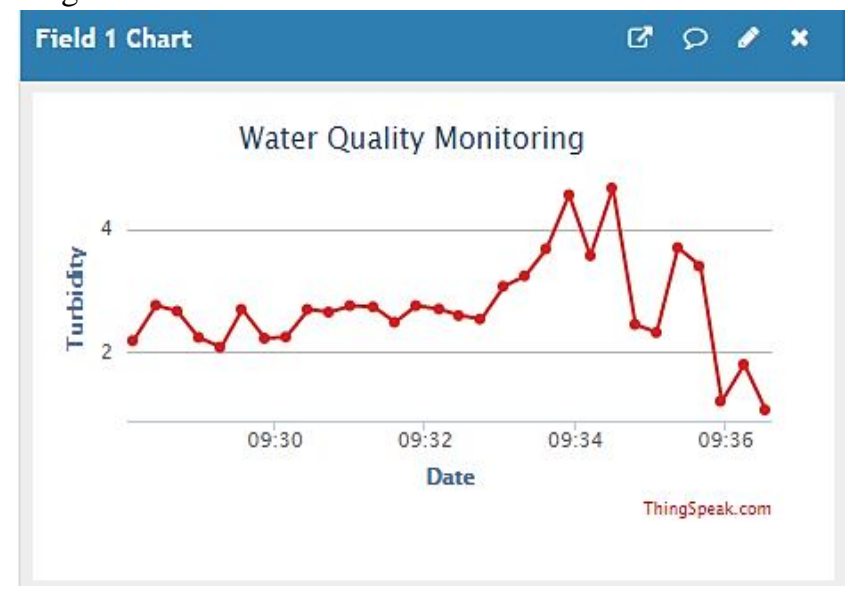

Figure 4: Graph showing variation of turbidity with time.

Field 2 Chart ए $0 \div x$

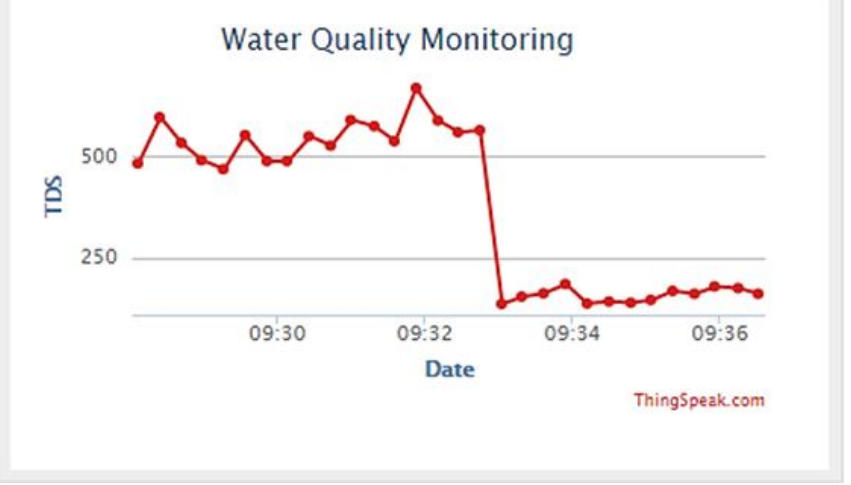

Figure 5: Graph showing variation of TDS with time. 
Kartik Maheshwari et al., International Journal of Emerging Trends in Engineering Research, 9(7), July 2021, 1020 - 1024

In order to evaluate the proposed system, data is collected from Water Flow Sensor and all data recorded is transferred to the ThingSpeak cloud. The data was divided into Flow Rate (L/min), Current Liquid Flow (ml/sec). Output Liquid Quantity (ml) to evaluate the system, as shown in figure 6. Also there is ThingSpeak gauge, as shown in figure 7, is proposed based on the transferred values by the water flow sensor which helps user monitor and control the water flow rate.

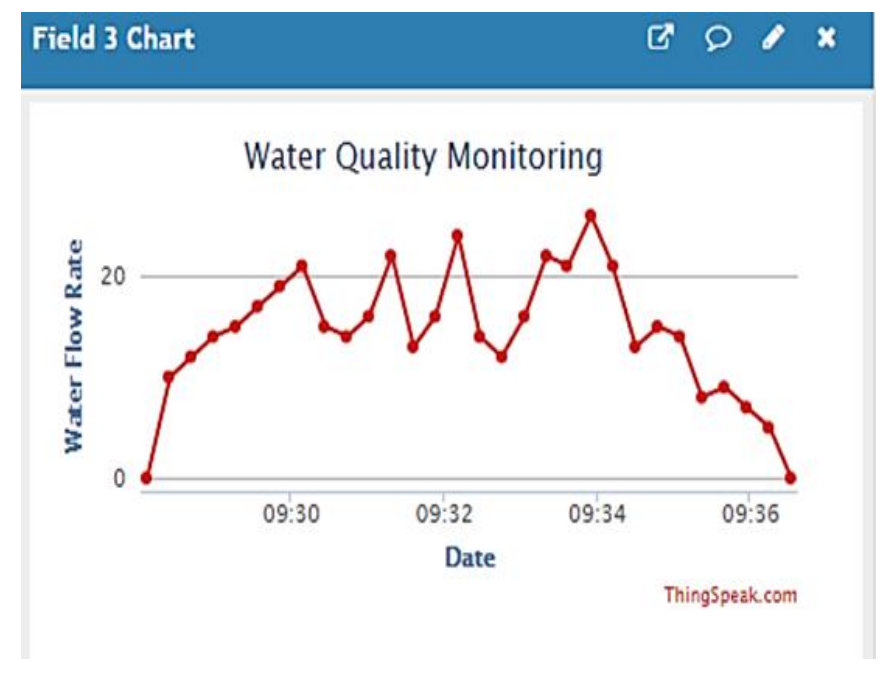

Figure 6: Graph showing variation of water flow rate with time.

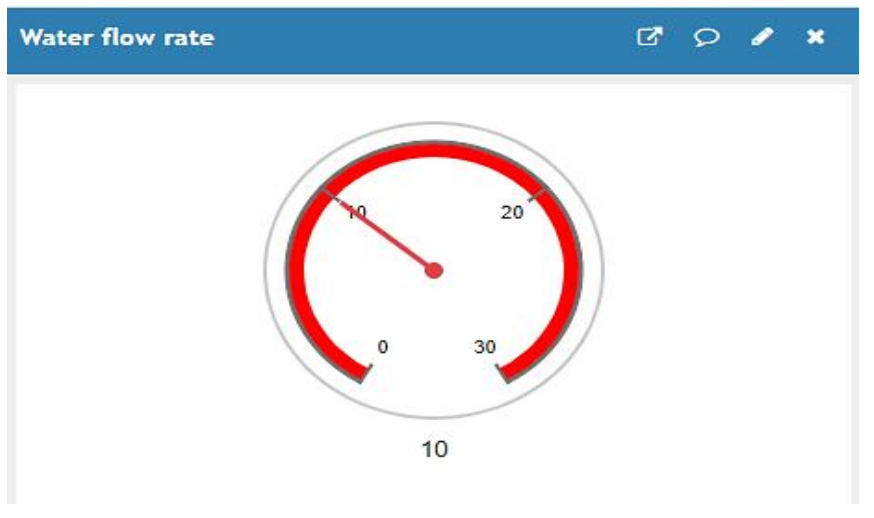

Figure 7:- Thingpeak Gauge for water flow sensor

When the turbidity and TDS values of water crosses the safety limit, it triggers an event in the IFTTT platform to send appropriate notifications to the user as shown in figure 8 .
High turbidity detected at July 1 .

$\underline{2021}$ at 10:34AM.

High turbidity detected at July 1 .

$\underline{2021}$ at 10:35AM.

High TDS value detected at July

1.2021 at $10: 40 \mathrm{AM}$.

High TDS value detected at July

1.2021 at 10:40AM.

\section{$+\quad$ Text message}

Figure 8: SMS notifications sent through IFTTT.

\section{FUTURE SCOPE}

This proposed system gives information to every user who depend on that plant. We can use more sensors to detect more parameters for the water quality analysis purposes. The supply of water can be controlled by interfacing relay for easy detection. This system can be used to monitor other water quality parameters. The operation is user-friendly. The system can be expanded to monitor hydrologic, air pollution, industrial and agricultural production and so on. It has widespread application and extension value.

\section{Applications:}

- This system can be used for both commercial and domestic purposes.

- Different water supply agencies.

- In health department for identification and cause of water diseases.

\section{CONCLUSION}

This paper has successfully improvised an intelligent water quality monitoring system. The system can be monitored from a PC and is also capable of sending a smart alert through IFTTT. It is a low cost and robust model that does not require people on duty. It provides quick and easy monitoring of turbidity and TDS level to ensure clean water is maintained continuously. ThingSpeak has provided a suitable environment for analyzing and comparing the sensor data as observed in graphics and smart alerts. As per the obtained results, the proposed system can be considered as suitable water quality monitoring system. Our system has made water quality testing more economical, convenient and reliable with timely feedback. 


\section{REFERENCES}

1. Kumar, S. S., Rao, B. V. S., \& Prasad J. R. (2020, September). Design and Development of a Water Quality Monitoring System by Using IoT. International Journal of Emerging Trends in Engineering Research, Vol. 8, pp. 6441 - 6447.

2. Chowdury, M. S. U., Emran, T. B., Ghosh, S., Pathak, A., Alam, M. M., Absar, N., ... \& Hossain, M. S. (2019). IoT based real-time river water quality monitoring system. Procedia Computer Science, 155, 161-168.

3. Pappu, S., Vudatha, P., Niharika, A. V., Karthick, T., \& Sankaranarayanan, S. (2017). Intelligent IoT based water quality monitoring system. International Journal of Applied Engineering Research, 12(16), 5447-5454.

4. Perumal, T., Sulaiman, M. N., \& Leong, C. Y. (2015, October). Internet of Things (IoT) enabled water monitoring system, in 2015 IEEE 4th Global Conference on Consumer Electronics (GCCE) (pp. 86-87). IEEE.

5. Koditala, N. K., \& Pandey, P. S. (2018, August). Water quality monitoring system using IoT and machine learning, in 2018 International Conference on Research in Intelligent and Computing in Engineering (RICE) ( $\mathrm{pp}$. 1-5). IEEE.

6. Huan, J., Li, H., Wu, F., \& Cao, W. (2020). Design of water quality monitoring system for aquaculture ponds based on NB-IoT. Aquacultural Engineering, 90, 102088.

7. Miry, A. H., \& Aramice, G. A. (2020). Water monitoring and analytic based ThingSpeak. International Journal of Electrical and Computer Engineering, 10(4), 3588.

8. Chen, Y., \& Han, D. (2018). Water quality monitoring in smart city: A pilot project. Automation in Construction, 89, 307-316.

9. Pasika, S., \& Gandla, S. T. (2020). Smart water quality monitoring system with cost-effective using IoT. Heliyon, 6(7), e04096.

10. Shu, T., Xia, M., Chen, J., \& De Silva, C. (2017). An energy efficient adaptive sampling algorithm in a sensor network for automated water quality monitoring. Sensors, 17(11), 2551.

11. Kamaludin, K. H., \& Ismail, W. (2017, December). Water quality monitoring with internet of things (IoT), in 2017 IEEE Conference on Systems, Process and Control (ICSPC) (pp. 18-23). IEEE. 